\title{
Echocardiographic diagnosis of fetal heart defects in mid trimester
}

\author{
I A PARNESS,${ }^{*} \mathrm{~S}$ B YEAGER, $\dagger \mathrm{S}$ P SANDERS,${ }^{*}$ B BENACERRAF, $\ddagger \mathrm{S}$ D COLAN,$*$ \\ AND R VANPRAAGH
}

Departments of *Pediatrics and \Pathology, Harvard Medical School; *Department of Cardiology, Children’s Hospital; and $\ddagger$ Department of Obstetrics and Gynecology, Brigham and Women’s Hospital, Boston, †Department of Pediatrics, West Virginia School of Medicine, Morgantown, and †Department of Pediatrics, University of Vermont School of Medicine, Burlington, USA

SUMmaRY One hundred and thirty five consecutive fetuses of between 16 and 23 weeks' gestation that were considered to be at high risk of having structural heart defects were examined prospectively to determine the reliability of echocardiography for diagnosing such defects in mid timester. Each echocardiogram was done in a standard manner and cardiac anatomy was analysed segmentally. Twelve fetuses were excluded from analysis because of lack of follow up. Of the remaining 123 fetuses, 109 had no evidence of heart disease when followed up. In this group the prenatal echocardiogram was normal in 105 and technically inadequate in four; thus there were no false positive diagnoses of heart disease in fetuses subsequently shown to have normal hearts. Fourteen had heart defects at follow up. The serious defect was correctly diagnosed prenatally in 10 of 14 cases, whereas in the other four the prenatal echocardiogram was considered normal. Some errors were made in diagnosing associated segmental defects particularly if the heart disease was complicated. Therapeutic abortion was carried out in seven cases; in five of the fetuses the prenatally diagnosed heart defect was the sole or an important contributing reason for the abortion. We conclude that echocardiography is a reliable method for diagnosing many heart defects in the mid trimester.

Ultrasonography has become a valuable and reliable technique for prenatal diagnosis of many fetal abnormalities. ${ }^{12}$ Techniques have been described for performing prenatal two dimensional, ${ }^{3-6}$ as well as $\mathrm{M}$ mode, , $^{5-8}$ and Doppler ${ }^{9}{ }^{10}$ echocardiography. These investigations have shown that prenatal echocardiography can identify normal cardiac anatomy at gestational ages ranging from about 17 weeks to full term. Many structural heart defects have been diagnosed in older fetuses ${ }^{11-15}$ with echocardiography, but there are few reports of the prospective diagnosis of heart defects in fetuses of less than 24 weeks' gestation. $^{6}{ }^{13} 16-18$ The accuracy of prenatal echocardiography has not been prospectively evaluated for the diagnosis of complex cardiac defects segment by segment, yet management of pregnancies at high risk of congenital heart defects requires diagnostic methods that are reliable at a stage of gestation when the option of terminating the pregnancy is still available.

We investigated the use of prenatal echocar- diography for diagnosing structural heart defects in fetuses of less than 24 weeks' gestation in a population considered at high risk of congenital heart disease.

\section{Subjects and methods}

Between December 1982 and July 1986 we examined 135 consecutive fetuses of less than 24 weeks' gestation in 133 pregnancies. Eighty examinations were done at the Children's Hospital, Boston, 41 were at West Virginia University Hospital (December 1982 to June 1985), and nine at the Medical Center Hospital of Vermont (July 1985 to June 1986). Five fetuses underwent a second examination either as a follow up for hydrops or because the first examination was technically inadequate. Twelve fetuses were excluded from the study: nine were lost to follow up, two died in utero and did not undergo necropsy, and one was therapeutically aborted without necropsy. The gesta- 
tional ages of the 123 included in the study ranged from 16 to 23 weeks at the time of examination (mean 20.5).

Risk factors prompting referral for prenatal echocardiography included: family history of congenital heart defect, ${ }^{19-21}$ maternal diabetes, ${ }^{22}$ maternal exposure to teratogenic agents during early gestation, ${ }^{23}$ chromosomal abnormalities or multiple congenital anomalies detected by prenatal screening, ${ }^{24}$ a congenital heart defect suspected on obstetric ultrasound examination, and fetal arrhythmias.

All examinations were done by three of the authors (IAP and SPS at the Children's Hospital, Boston, and SBY at West Virginia University Hospital and the Medical Center Hospital of Vermont). Prenatal echocardiograms were done with an ATL Mark 600 or Hewlett Packard cardiac imager equipped with a short or medium focus $5.0 \mathrm{mHz}$ transducer. Two dimensional echocardiographic imaging was supplemented by two dimensional directed M mode or Doppler cardiography, or both, in patients with abnormal rhythms or anatomy. Examinations were recorded on 1/2" video cassette tape for review in real time, slow motion, and stop frame modes.

The examination was done with the mother supine or in a lateral decubitus position. If the position of the fetus was unfavourable for cardiac imaging, the mother was asked to change position or walk about the laboratory. If the position could not be improved, the patient was asked to return on another day for examination.

Each examination was done in a standard manner. The position and orientation of the fetus was determined using long and short axis scans of the fetal trunk. ${ }^{3}$ The fetal cardiovascular anatomy was then analysed segment by segment as previously described in neonates. ${ }^{25-27}$ Visceroatrial situs was calculated from a transverse view of the abdomen near the diaphragm by evaluating the respective positions of the inferior vena cava, the descending aorta, and the spine, as well as the pattern of the venous connections (fig 1). ${ }^{28}$ Long and short axis views of the trunk were used to provide short and long axis views, respectively, of the fetal heart. ${ }^{3} \mathrm{~A}$ modified long axis view of the trunk was used to visualise the aortic arch. ${ }^{3}$ Using these views, the veins, atriums, atrial septum, atrioventricular valves, ventricles, ventricular septum, semilunar valves, and great arteries were sequentially scanned in at least two orthogonal planes.

The recorded examination was reviewed and an anatomical diagnosis assigned using the nomenclature proposed by VanPraagh et al. ${ }^{29}$ If any examination failed to visualise any cardiac segment adequately, the study was considered technically


Fig 1 Transverse sections of the fetal trunk at the level of the diaphragm showing the relative positions of the aorta, inferior vena cava and spine. a-Case 2 . Note the right anterior position of the inferior vena cava and the left posterior position of the aorta. $b-C a s e 8$ (heterotaxy). A dilated azygos vein is posterior to the aorta associated with absence of the renal to hepatic segment of the inferiorvena cava.c-Case 9. Because of aleft diaphragmatichernia, the aorta and inferior vena cava are juxtaposed to the left of the spine (similarto asplenia). Ao: aorta, Az: azygos vein, IVC: inferiorvena cava, l: left, r: right, Sp:spine, and p:posterior. 
inadequate. Because, however, it was often difficult to see pulmonary venous connections and the aortic isthmus clearly, studies that defined these structures indistinctly were considered technically adequate. Technically inadequate examinations are reported as such and were not excluded from analysis.

The result of each prenatal echocardiogram was discussed with the parents, the referring obstetrician, and (if concerned) the paediatric cardiologist. The presumed limitations of the test, specifically for the diagnosis of atrial septal defect, ventricular septal defect, patent ductus arteriosus, coarctation of the aorta, and minor abnormalities of the valves were discussed with the parents before the examination and again afterward in those cases in which no abnormality was detected.

If a cardiac defect was diagnosed, the nature of the defect including anatomy, physiology, prognosis, and possible postnatal treatment was explained to the parents and physicians. The parents and primary physicians were encouraged to contact us again after the examination if questions arose. The decision to continue or terminate the pregnancy was made by the parents in consultation with the primary physician. If the pregnancy was continued the parents were referred to a paediatric cardiologist who made appropriate plans for perinatal management.

The outcome of live births was found out by telephone interview with a parent or primary physician, or both, one month to one year postnatally. The infant was considered normal if there were no findings suggestive of a congenital heart defect at routine paediatric physical examination $(n=109)$. All infants with clinically suspected cardiac defects were examined by a paediatric cardiologist. The results of clinical examination, two dimensional echocardiography, cardiac catheterisation, and angiography or surgical inspection, or both, were obtained in these eight cases. Necropsy reports were obtained in all 10 cases in which the examination was performed.

\section{Results}

In 109 cases there was no evidence of congenital heart disease at follow up. In 105 of these the prenatal echocardiogram was normal, and in the other four cases the examination was technically inadequate.

Fourteen of $123(11 \%)$ were confirmed to have heart defects either at clinical follow up or at necropsy. A cardiac defect had been diagnosed prenatally in 10 of the 14 cases. Six of these 10 were therapeutically aborted and one fetus died in utero at 33 weeks' gestation with severe hydrops fetalis.
Of the remaining three infants who were born alive, two died in the neonatal period-one of the heart defect and the other of neonatal hepatitis. The third died at the age of $2 \frac{1 / 2}{2}$ months after a viral infection. Necropsy confirmed the serious heart defects diagnosed by prenatal echocardiography in all 10 cases. Serious defects that were diagnosed were: Ebstein's anomaly $(n=1)$, tricuspid regurgitation $(\mathrm{n}=1)$, pulmonary stenosis with hypoplastic right ventricle $(n=1)$, tetralogy of Fallot with pulmonary atresia and complete common atrioventricular canal $(n=1)$, hypoplastic left heart syndrome $(n=2)$, and complex heart disease with heterotaxy $(n=3)$ (table 1).

Defects were not diagnosed prenatally in four of the 14 fetuses that were subsequently found to have congenital heart defects (table 2). The lesions in those four cases were: patent ductus arteriosus $(n=1)$, moderate sized apical muscular ventricular septal defect $(n=1)$, midmuscular ventricular septal defect $(n=1)$, short segment coarctation of the aorta $(n=1)$, and atrial septal defect secundum $(n=1)$. In the infant with persistent patent ductus arteriosus spontaneous closure occurred when a few weeks old. The infant with coarctation and ventricular septal defect had the coarctation repaired when 3 weeks old, and the ventricular septal defect subsequently closed spontaneously. The other infant with a ventricular septal defect (age 12 months) does not at the time of writing seem to require operation. The atrial septal defect secundum was an incidental finding at necropsy following therapeutic abortion for other abnormalities.

The parents of four fetuses with prenatally diagnosed heart defects chose to continue the pregnancies after counselling. Two of these fetuses (cases 4 and 7) were born alive but died in the neonatal period despite management of the heart defects. A third fetus (case 6) died in utero at 33 weeks' gestation of fetal hydrops. The remaining fetus (case 10) was born at full term and underwent palliative ligation of patent ductus arteriosus and pulmonary artery banding. The infant subsequently developed pneumonia and died when $2 \frac{1}{2}$ months old.

\section{Discussion}

In our study, adequate two dimensional echocardiograms were obtained in $97 \%$ of fetuses before 24 weeks' gestation. We correctly excluded structural heart defects in all fetuses that were subsequently found to be normal and in which technically adequate echocardiograms could be obtained; no normal fetus was diagnosed as having a structural heart defect by prenatal echocardiography. 










1142 Parness, Yeager, Sanders, Benacerraf, Colan, and VanPraagh

Table 2 Heart defects not diagnosed prenatally

\begin{tabular}{|c|c|c|c|c|}
\hline $\begin{array}{l}\text { Case } \\
\text { No }\end{array}$ & $\begin{array}{l}\text { Gestational } \\
\text { age (weeks) }\end{array}$ & $\begin{array}{l}\text { Indication for } \\
\text { examination }\end{array}$ & Echocardiographic diagnosis & Final diagnosis and method of confirmation \\
\hline 11 & 20 & $\begin{array}{l}\text { Previous child with } \\
\text { congenital heart } \\
\text { disease }\end{array}$ & $\begin{array}{l}1\{\mathrm{~S}, \mathrm{D}, \mathrm{S}\}^{*} \\
2 \text { No structural heart defects }\end{array}$ & $\begin{array}{l}\text { Born alive (angiography, echocardio- } \\
\text { graphy, clinical observation) } \\
1\{\mathrm{~S}, \mathrm{D}, \mathrm{S}\}^{*} \\
2 \text { Moderate midmuscular ventricular septal } \\
\text { defect } \\
3 \text { Severe short segment coarctation of } \\
\text { aorta }\end{array}$ \\
\hline 12 & 20 & $\begin{array}{l}\text { Previous child with } \\
\text { congenital heart } \\
\text { disease }\end{array}$ & $\begin{array}{l}1\{\mathrm{~S}, \mathrm{D}, \mathrm{S}\}^{*} \\
2 \text { No structural heart defects }\end{array}$ & $\begin{array}{l}\text { Born alive (echocardiography, clinical } \\
\text { observation) } \\
1\{\mathrm{~S}, \mathrm{D}, \mathrm{S}\}^{*} \\
2 \text { Moderate apical muscular ventricular } \\
\text { septal defect }\end{array}$ \\
\hline 13 & 23 & Fetal arrhythmia & $\begin{array}{l}1\{\mathrm{~S}, \mathrm{D}, \mathrm{S}\}^{*} \\
2 \text { No structural heart defects }\end{array}$ & $\begin{array}{l}\text { Born alive (clinical observation) } \\
1\{\mathrm{~S}, \mathrm{D}, \mathrm{S}\}^{*} \\
2 \text { Patent ductus arteriosus }\end{array}$ \\
\hline 14 & 20 & $\begin{array}{l}\text { Amniocentesis } 46,3 p^{-} \\
\text {Other abnormalities }\end{array}$ & $\begin{array}{l}1\{\mathrm{~S}, \mathrm{D}, \mathrm{S}\}^{*} \\
2 \text { No structural heart defects }\end{array}$ & $\begin{array}{l}\text { Therapeutic abortion (necropsy) } \\
1 \text { S , D,S }\}^{*} \\
2 \text { Atrial septal defect secundum } \\
3 \text { Renal and skeletal abnormalities }\end{array}$ \\
\hline
\end{tabular}

${ }^{*}$ Segmental notation described by VanPraagh et al. ${ }^{29}$

Our results also show that many forms of congenital heart disease, including complex defects, can be diagnosed in fetuses before 24 weeks' gestation using two dimensional echocardiography. Thus the information necessary to make rational decisions about continuing or terminating pregnancies at high risk of congenital heart defects can be obtained in nearly all patients. In five of our cases the knowledge that the fetuses had severe heart defects was influential in the decision to terminate the pregnancy. In the three cases in which severe cardiac defects were diagnosed prenatally and the pregnancies were carried to full term, the family and responsible physician were prepared for the birth of an infant with congenital heart disease.

The three complex cases of heterotaxy illustrate both the potential for accurate segmental diagnosis and the potential for error in such an analysis. In case 8 a complex defect was correctly diagnosed in nearly all details. Persistent left superior vena cava and ipsilateral pulmonary venous connection were not seen prenatally (figs 1 and 2 , and table 2). In case 9 , though double outlet single right ventricle was correctly diagnosed, several errors were made in the segmental diagnosis. The inferior vena cava and descending aorta were to the left of the spine at the diaphragm suggesting visceroatrial heterotaxy (fig 1c). Displacement of the liver to the left by the left diaphragmatic hernia disorted the relationship between the inferior vena cava and spine in this fetus with normal visceroatrial situs. The anomalous pulmonary venous connection to the left vertical vein was not recognised prenatally. The hypoplastic left atrium with mitral atresia could not be seen adequately, and the dilated right atrium and tricuspid valve were misinterpreted as a common atrium and common atrioventricular valve. Functionally, the 8 most important error was in mistaking the enlarged pulmonary artery and ductus arteriosus for a large aorta. We believe that this was partly a result of our? heightened suspicion of asplenia (which is commonly associated with malposition of the great arteries and pulmonary stenosis), and partly because of the inability to resolve as separate structures the hypoplastic aorta and the ductus arteriosus (fig 3). In retrospect a branch pulmonary artery could be seen arising from the anterior vessel, identifying it as the pulmonary trunk. Though in this case the errors in diagnosis did not influence the management appreciably, some of the errors might be important if the heart disease were an isolated abnormality.

In case 10 , our failure to identify the inferior vena cava led us to suspect that there was an interrupted inferior vena cava with azygous continuation, but this was not so. As in case 9, a hypoplastic left atrium was not recognised, and a dilated right atrium was misinterpreted as a common atrium. Visualisation of the atrioventricular valve and ventricular morphology was not good enough to identify the ventricular loop, and a posterior muscular ventricular septal defect was mistaken for an atrioventricular canal defect. In two additional fetuses (cases 1 and 2), tricuspid regurgitation seemed to restrict the excursion of the pulmonary valve resulting in an overestimation of the degree of obstruction. ${ }^{30}$ 

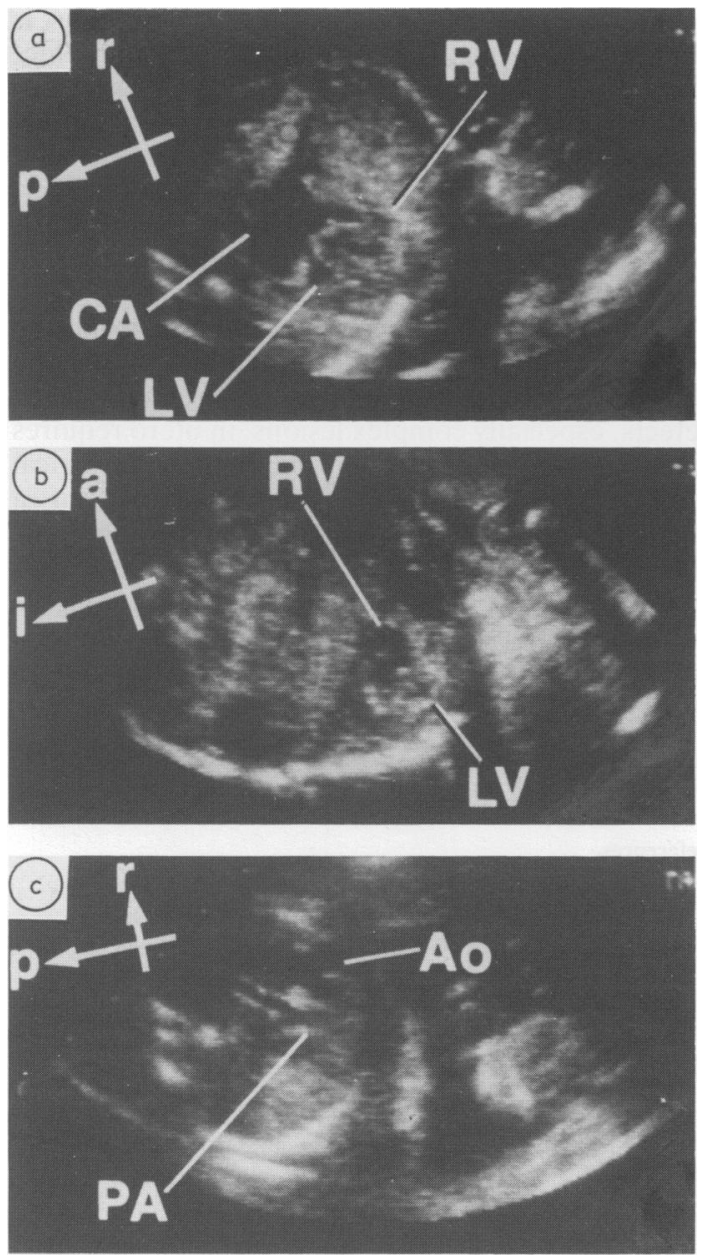

Fig 2 Case 8 (heterotaxy). a-Four chamber view of the heart showing common atrium, common atrioventricular valve, and right ventricular dominance. $b$-Short axis view of the ventricles showing large right ventricle and hypoplastic left ventricle. c-Transverse cut through the great arteries showing large aorta and hypoplastic pulmonary arteries. a: anterior, CA: common atrium, $i$ : inferior, $L V$ : left ventricle, $P A$ : pulmonary artery, $R V$ : right ventricle, Ao: aorta, r: right, and p: posterior.

In summary, diagnostic errors were made in the evaluation of each cardiac segment. Systemic and pulmonary venous anomalies, were particularly difficult to visualise in fetuses of less than 24 weeks' gestation, though improved resolution and new techniques (such as colour flow Doppler) may improve the sensitivity. On two occasions a small atrial chamber was not recognised and this led to a false diagnostic impression of a single atrium. In one

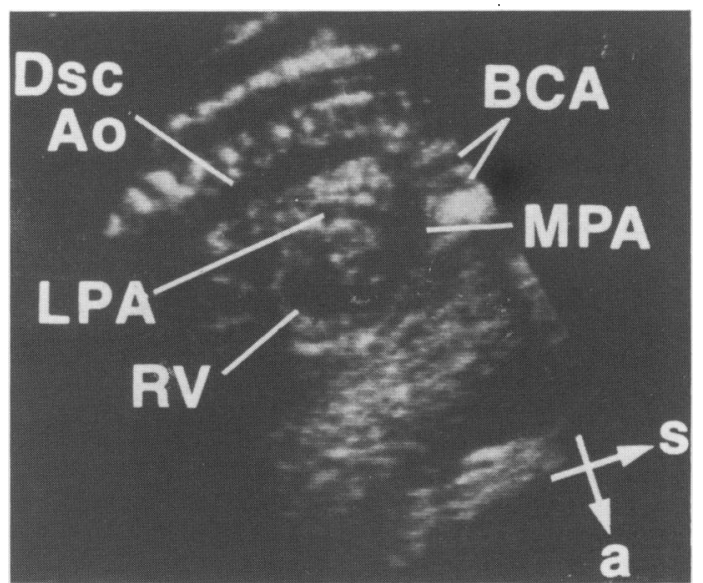

Fig 3 Case 9. Parasagittal view in fetus with double outlet single right ventricle showing how the main pulmonary artery and ductus arteriosus can look like the aortic arch. Note the left pulmonary artery arising from the main pulmonary artery. BCA: brachiocephalic arteries, Dsc Ao: descending aorta, LPA: left pulmonary artery, MPA: main pulmonary artery, s: superior, $R V$ : right ventricle, and a: anterior.

case the presence of mitral atresia led to the misdiagnosis of a single common atrioventricular valve, and on two occasions imaging was not good enough to see ventricular looping. Evaluation of the infundibular and semilunar valve segments of the heart was largely successful, though in two cases the presence of severe tricuspid regurgitation influenced the assessment of the pulmonary valve.

Our experience suggests that some additional defects are unlikely to be diagnosed consistently by prenatal echocardiography, at least before 24 weeks' gestation. We missed muscular ventricular septal defects and coarctation of the aorta largely because of limitations in resolution of the imaging devices. None of these defects could be definitely diagnosed, even in retrospect. Other defects that might not be detected for the same reason include abnormalities of the valves such as bicommissural aortic valve or congenital mitral stenosis. Normal fetal physiology results in a widely patent foramen ovale, precluding reliable prenatal diagnosis of atrial septal defect secundum (fig 4). Prenatal echocardiography cannot predict postnatal patency of the ductus arteriosus, and in some cases coarctation of the aorta may develop postnatally in association with closure of the ductus arteriosus. ${ }^{31}$

Because a fetus with a normal two dimensional echocardiogram was not re-examined again, we cannot exclude the possibility that some defects missed at the first examination might be detected 



Fig 4 Four chamber views of the heart illustrating the difficulty in diagnosing atrial septal defect secundum. a-Case 12 with intact atrial septum at follow up, and $b$-Case 14 with secundum atrial septal defect at necropsy. LA: left atrium, and RA: right atrium.

later in gestation. None the less, most of the defects that might be difficult or impossible to diagnose using prenatal echocardiography can be treated surgically with low risk. It seems unlikely that parents would choose to terminate a pregnancy because of detection of one of these lesions.

Though the postnatal clinical evaluation used to establish normality in our patients is not proof of the absence of a heart defect, it is the most common way of detecting such defects. Abnormalities that may be missed by routine clinical examination in young infants include atrial septal defects, mild coarctation of the aorta; and minor valvular defects, all of which would be unlikely to be diagnosed by fetal echocardiography. Thus the clinical examination seems adequate to diagnose those lesions that one hopes to detect by prenatal echocardiography.
The high yield of cardiac defects in our series is the result of the highly selected nature of our patient population. The disproportionate number of fetuses with unusual and severe anomalies was largely because of referral after routine obstetric ultrasound examination had suggested the presence of a heart defect. Similar skewing of the distribution towards more severe lesions was noted in the series reported by Allen et al. ${ }^{32}$

Though prenatal echocardiography is a promising and useful technique, its limitations should be recognised. Reliable diagnosis of structural heart defects, especially complex lesions, in utero requires extensive knowledge of normal and pathological cardiac anatomy. Despite meticulous use of a segmental approach to prenatal echocardiographic diagnosis of structural heart defects we have been unable to achieve the diagnostic accuracy attainable postnatally. We hope that as techniques improve prenatal diagnosis will become as accurate as postnatal diagnosis.

This study was supported in part by training grant No 5T32HLO 752-03 from the National Institutes of Health.

\section{References}

1 Dunne MG, Johnson ML. The ultrasonic demonstration of fetal abnormalities in utero. $J$ Reprod Med 1979;23:195-206.

2 Sabbagha RE, Shkolnik A. Ultrasound diagnosis of fetal abnormalities. Semin Perinatol 1980;4:213-27.

3 Allan LD, Tynan MJ, Campbell S, Wilkinson JL, Anderson $\mathrm{RH}$. Echocardiographic and anatomical correlates in the fetus. Br Heart $J$ 1980;44:444-51.

${ }^{4}$ Lange LW, Sahn DJ, Allen HD, Goldberg SJ, Anderson C, Giles H. Qualitative real-time cross-sectional echocardiographic imaging of the human fetus during the second half of pregnancy. Circulation 1980;62:799-886.

5 Devore GR, Donnerstein RL, Klienman CS, Platt LD, Hobbins JC. Fetal echocardiography I. Normal anatomy as determined by real-time-directed M-mode ultrasound. Am J Obstet Gynecol 1982;144:249-60.

${ }^{6}$ Wladimiroff JW, Stewart PA, Vosters RPL. Fetal cardiac structure and function as studied by ultrasound. Clin Cardiol 1984;7:239-53.

7 Sahn DJ, Lange LW, Allen HD, et al. Quantitative real-time cross-sectional echocardiography in the developing normal human fetus and newborn. Circulation 1980;62:588-97.

${ }^{8}$ St John Sutton MG, Gewitz HM, Shah B, et al. Quantitative assessment of growth and function of the cardiac chambers in the normal human fetus: a prospective longitudinal echocardiographic study. Circulation 1984:69:645-54.

9 Maulik D, Nanda NC. Saini VD. Fetal Doppler echocardiography: methods and characterization of normal and abnormal hemodynamics. Am J Cardiol 1984;53:572-8.

10 Reef KL, Meijboon EJ, Sahn DJ, et al. Cardiac Doppler flow in human fetuses. Circulation 1986;52:41-6.

$"$ Kleinman CS, Hobbins JC, Jaffe CC, Lynch DC, Tainer NS. Echocardiographic studies of the human fetus: Prenatal diagnosis of congenital heart disease and cardiac dysrhythmias. Pediatrics 1980:65:1059-67.

12 Kleinman CS, Donnerstein RL, DeVore GR, et al. Fetal echocardiography for evaluation of in utero congestive heart failure. $N$ Engl J Med 1982;306:568-75.

13 Allan LD, Crawford DC, Anderson RH, Tynan MJ. Echocar- 
diographic and anatomical correlations in fetal congenital heart disease. Br Heart J 1984;52:542-8.

${ }^{14}$ Kleinman CS, Santulli TV Jr. Ultrasonic evaluation of the fetal human heart. Semin Perinatol 1983;7:90-101.

15 Maulik D, Nanda NC, Moodley S, Saini VD, Thiede HA. Application of Doppler echocardiography in the assessment of fetal cardiac disease. Am J Obstet Gynecol 1985;151:951-7.

16 Allan LD, Tynan M, Campbell S, Anderson RH. Identification of congenital cardiac malformations by echocardiography in the mid trimester fetus. Br Heart J 1981;46:358-62.

17 Silverman NH, Enderlein MA, Golbus MS. Ultrasonic recognition of aortic valve atresia in utero. Am J Cardiol 1984;53:391-2.

${ }^{18}$ Stewart PA, Becker AE, Wladimiroff JW, Essed CE. Left atrial isomerism associated with asplenia: Prenatal echocardiographic detection of complex congenital cardiac malformations. J Am Coll Cardiol 1984:4:1015-20.

${ }^{19}$ Nora JJ, Wolf RR. Recurrence risks in the family. In: Kidd BS, Rowe RD, eds. The child with congenital heart disease after surgery. New York: Futura, 1976:451-60.

${ }^{20}$ Whittemore R, Hobbins JC, Engle MA. Pregnancy and its outcome in women with and without surgical treatment of congenital heart disease. Am J Cardiol 1982;50:641-51.

21 Allan LD, Crawford DC, Chita SK, Anderson RH, Tynan MJ. The familial recurrence of congenital heart disease. $\mathrm{Br}$ Heart $J$ 1985;54:613.

22 Rowland TW, Hubbell JP, Nadas AS. Congenital heart disease in infants with diabetic mothers. J Pediatr 1973;83:815-20.

${ }^{23}$ Nora JJ. Etiologic aspects of heart diseases. In: Adams FH, Emmanouilides GC, eds. Moss' heart disease in infants, children, and adolescents. Baltimore: Williams \& Wilkins, 1983. 2-10.

${ }^{24}$ Noonan JA. Syndromes associated with cardiac defects. In:
Engle MA, ed. Pediatric cardiovascular disease. Philadelphia: FA Davis, 1981:97-117.

${ }^{25}$ Sanders SP. Echocardiography and related techniques in the diagnosis of congenital heart defects. Part I: veins, atria, and interatrial septum. Echocardiography 1984;1:185-217.

${ }^{26}$ Sanders SP. Echocardiography and related techniques in the diagnosis of congenital heart defects. Part II: atrioventricular valves and ventricles. Echocardiography 1984;1:333-91.

${ }^{27}$ Sanders SP. Echocardiography and related techniques in the diagnosis of congenital heart defects. Part III: conotruncus and great arteries. Echocardiography 1984;1:443-93.

${ }^{28}$ Huhta JC, Smallhorn JF, Macartney FJ. Two-dimensional echocardiographic diagnosis of situs. Br Heart J 1982;48:97-108.

29 VanPraagh R, Weinberg PM, Matsuoka R, Van Praagh S. Malpositions of the heart. In: Adams FH, Emmanouilides GC, eds. Moss' heart disease in infants, children, and adolescents. Baltimore: Williams \& Wilkins, 1983:422-57.

30 Yeager SB, Parness IA, Sanders SP. Severe tricuspid regurgitation simulating pulmonary atresia in the fetus. Am Heart $J$ 1988;115:906-8.

31 Hosy, Anderson RH. Coarctation, tubular hypoplasia, and the ductus arteriosus. Histological study of 35 specimens. Br Heart J 1979;41:268-74.

32 Allan LD, Crawford DC, Anderson RH, Tynan M. Spectrum of congenital heart disease detected echocardiographically in prenatal life. Br Heart J 1985;54:523-6.

Correspondence and requests for reprints to Dr Ira A Parness, Department of Cardiology, The Children's Hospital, 300 Longwood Avenue, Boston, MA 02115, USA.

Accepted 26 May 1988 